\title{
Coal permeability model on the effect of gas extraction within effective influence zone
}

\author{
Jing Xie $\cdot$ Mingzhong Gao $\cdot$ Bin Yu $\cdot$ Ru Zhang $\cdot$ \\ Wencheng Jin
}

Received: 18 March 2015/Accepted: 8 May 2015/Published online: 30 May 2015

(C) Springer International Publishing Switzerland 2015

\begin{abstract}
In situ gas extraction is the main measure adopted by mines to achieve mining safety standards. Coal permeability is significantly influenced by coal shrinkage during gas release. Based on effective stress and additional damage that resulted from gas extraction, a unique model was proposed to describe the spatial and temporal distribution of coal permeability within the effective influence zone. Calculation models for the conditions of one and two extracting boreholes were developed. A parametric study on both two models was also conducted, in which the effect of extraction time, extraction pressure, interval between two boreholes, and extraction pressure combination were qualitatively analyzed. The results demonstrated
\end{abstract}

\footnotetext{
J. Xie · M. Gao $(\varangle) \cdot$ R. Zhang · W. Jin

Department of Geotechnical Engineering, State Key

Laboratory of Hydraulics and Mountain River

Engineering, College of Water Resource and

Hydropower, Sichuan University, Chengdu 610065,

China

e-mail: gaomingzhong@163.com

J. Xie

e-mail: xiejing200655@163.com

R. Zhang

e-mail: zhangru@scu.edu.cn

W. Jin

e-mail: kingofjwc@gmail.com

B. $\mathrm{Yu}$

Datong Coal Mine Group, Datong 037003, China

e-mail: yubin0352@126.com
}

that with the increase of extraction time, gas extraction can result in less permeability reduction in the beginning but can enhance permeability. Coal permeability obviously increases when extraction time increases but gradually stabilizes, presenting "high middle and low around" surrounding the extracting borehole. Meanwhile, a decreasing relative amplification implies that permeability ratio does not increase linearly with the increase in extraction pressure. Both intervals between two extracting boreholes and different combinations of extraction pressure significantly influence the distribution of coal permeability. A comparison with some previous permeability studies was conducted to validate the proposed model, and the predicted evolution results matched the permeability testing data. In conclusion, the proposed model is consistent with the phenomenon in real engineering, and the model results can provide preliminary guidance for the design of extracting borehole distribution.

Keywords Gas extraction - Coal permeability · Gas pressure $\cdot$ Parametric study

\section{Introduction}

Considerable global energy is produced by coal combustion, and coal is still the main natural resource of humans, especially in China. However, the methane content and pressure in coalbeds continue to increase 
as coal is excavated deeply. Considering that gas is a type of clean energy, it must be extracted before any mining action is performed. Miners solve this issue by drilling a borehole matrix for extraction. Consequently, determining the permeability evolution around the borehole when gas is extracted in situ is necessary.

Given that coal and the embedded gas have a typical dual-porosity/permeability system that contains a porous matrix surrounded by fractures (Seidle et al. 1992), the permeability of coal mass is a complex parameter affected by numerous factors. Experimental efforts and model developments have been exerted to reveal coal-gas permeability and its evolution. Stress state and effective stress are always considered as an important factor for coal permeability (Gray 1987; McKee et al. 1987; Palmer and Mansoori 1996; Enever and Henning 1997). Because of the pores in coal matrix, the percolation of coal methane becomes a reality. The geometry of pores and porosity value are directly related to coal permeability (Reiss 1980; McKee et al. 1987; Seidle and Huitt 1995). Gas adsorption/desorption is a well-known phenomenon that results in coal swelling/shrinkage and is regarded as a key factor for permeability behavior in coalbed methane recovery (Pan and Connell 2007; Pan et al. 2010). Besides, coal permeability is also affected by other factors, such as different gases (Chen et al. 2011; Siriwardane et al. 2009), temperature (Hu et al. 2010), and wettability (Han et al. 2010).

To better understand these effects on coal permeability, various permeability models have also been proposed based on specific conditions. Shi and Durucan (2004a, b) used the conclusion of Gray (1987) and considered a pore pressure-dependent permeability model for gas desorbing coalbeds under uniaxial strain conditions. Palmer and Mansoori (1996) proposed a widely used model (called P\&M model) in which permeability was a function of effective stress and shrinkage. Numerous studies have been conducted based on the P\&M model (Pekot and Reeves 2002; Palmer et al. 2007; Clarkson 2009). Cui and Bustin (2005) developed a coal permeability model based on the volumetric strain induced by gas desorption and storage pressure. Connell et al. (2010) proposed a coal permeability model under a triaxial stress state. Liu and Rutqvist (2010) explicitly considered the interaction of fracture matrix and proposed the concept of swelling stress based on the effect of gas pressure change and matrix swelling or shrinkage on coal permeability. $\mathrm{Wu}$ et al. (2011) represented heterogeneous swelling processes, which proved that coal swelling is a heterogeneous process that depends on the distribution of coal voids. Izadi et al. (2011) recently represented coal heterogeneity by studying the specified damage zone in the vicinity of fracture walls.

The abovementioned studies have contributed to the mechanisms of gas adsorption/desorption, matrix swelling, and stress changing, which have a significant value in engineering. However, damage to the matrix of geo-materials induced by real engineering, such as roadway excavations, borehole drilling, gas extraction, and coal mining, will significantly influence the porefracture system. Hu et al. (2014) conducted studies on the effects of roadway and borehole excavations on effective stress and permeability redistributions. Xie et al. (2013) proposed the concept of mining-enhanced permeability for the first time. This concept mostly focused on the change in coal-mass permeability caused by coal mining. However, little literature can be found on permeability induced by gas extraction damage. Gas extraction is a process of releasing gas, which will induce coal-matrix shrinkage and increase its effective stress. Both effects will significantly affect coal permeability. Harpalani and Schraufnagel (1990) believed that coal permeability to methane increases with decreasing gas pressure despite increased effective stress. Zhu et al. (2013) considered the coal-matrix damage induced by gas adsorption/desorption to explain the change in coal permeability under constant effective stress. Given the effect of extraction pressure, gas extraction will cause faster gas desorption, and the coal-matrix damage induced by coal-matrix shrinkage cannot be neglected.

A coal-gas permeability model that incorporates the change in effective stress and coal-matrix damage around the extracting borehole was developed in this manuscript, which considered the additional damages caused by gas extraction. This goal was achieved through explicit development of the relationship between damage variable and coal permeability. And simple calculations of the permeability ratio based on the parameters from the No. 8 Mine of Pingdingshan Coal Mining Group in China were conducted. This model can be used to evaluate the effect of gas extraction and analyze the evolution of coal permeability spatially and temporally, which can lay a basic foundation for the design of gas extraction, including extraction time, extraction pressure and borehole 
distribution. In this paper, some related concepts and assumptions are discussed. The coal permeability model for one and two boreholes is also presented. Finally, a parametric study and a discussion on model results are conducted.

\section{Coal permeability model with gas extraction}

\subsection{Concepts and basic theories}

Presenting the concept of effective influence zone is necessary prior to studying the evolution of coal-mass permeability during gas extraction. In real engineering gas extraction, gas pressure will obviously decrease within a certain region to the extracting borehole center but will have slight or no change in the farther region. Thus, the region that gas pressure obviously changes can be called effective influence zone, as shown in Fig. 1. The effective zone is a complex subject connected to multiple factors, such as gas pressure, extraction time, extraction pressure, permeability coefficient, coal-mass absorptive properties, and fracture network distribution. The coal-mass permeability discussed in this paper is within the effective influence zone of gas extraction.

Pore-fracture structures in coal mass are the main galleries for gas migration and extraction (Pan and Connell 2012). Therefore, coal-mass permeability has an effective relationship with voids or fracture. Fracture aperture is one of the most important factors of fracture permeability, which is generally a function of normal stress (Jaeger et al. 2007). As a result, a

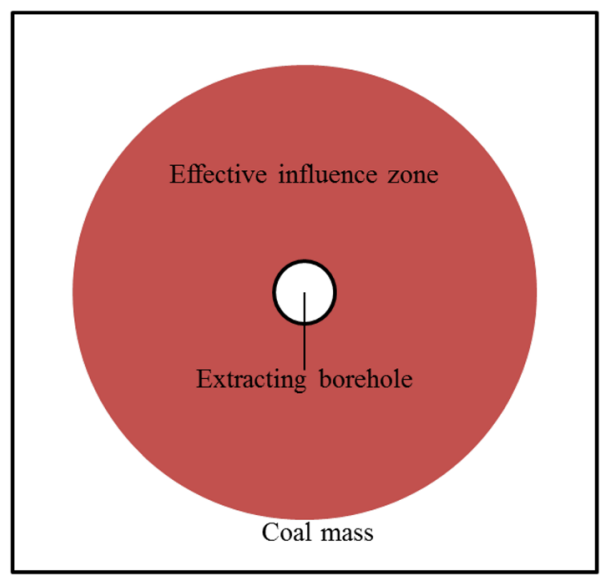

Fig. 1 Effective influence zone of gas extraction relationship between normal stress (effective stress) and coal-mass permeability is easily developed. Based on the cubic law, the relationship between coal-mass permeability and effective stress is given as follows (Liu and Rutqvist 2010):

$\frac{k_{1}}{k_{0}}=\left[\frac{\eta+e^{-C_{f} \sigma_{1}}}{\eta+e^{-C_{f} \sigma_{0}}}\right]^{3}$

where $k_{1}$ and $k_{0}$ are the coal-mass permeability for effective stress $\sigma_{1}$ and $\sigma_{0}$, respectively. In the parameter $\eta=b_{r} / b_{f}, b_{r}$ and $b_{f}$ are the residual fracture aperture and the stress-sensitive portion of the fracture aperture, respectively. The parameter $C_{f}$ is the fracture compressibility. Considering no residual fracture aperture remains, Eq. (1) can be simplified as follows (Liu and Rutqvist 2010):

$\frac{k_{1}}{k_{0}}=\exp \left[-3 C_{f}\left(\sigma_{1}-\sigma_{0}\right)\right]$

More detailed description regarding the abovementioned equations can be found in Liu and Rutqvist (2010). $\sigma_{0}$ and $\sigma_{1}$ are often regarded as two different stress states. However, the abovementioned equation considered only the effect of effective stress on fractures, which already existed, and neglected the deformation and damage of the coal matrix.

For a coal-fracture element, the change in stress state (especially effective stress) will have a significant effect on permeability properties. The change in permeability properties will also influence the stress state (Meng et al. 2011; Jasinge et al. 2011). Therefore, the relationship between coal matrix and fluid (like gas) is interactive and mutually constrained. With regard to gassy coal seams, coal-mass element is regarded as a coal fracture filled with gas. Based on Biot's theory, the effective stress in a coal-fracture element can be defined as follows (Jaeger et al. 2007):

$\sigma=\sigma_{t}-\alpha p$

where $\sigma$ is the effective stress, $\sigma_{t}$ is the total stress, $p$ is the fluid pressure, and $\alpha$ is Biot's coefficient.

\subsection{Coal permeability model with damage induced by gas extraction}

The following assumptions are considered in the model: (1) the coal-fracture element is full of gas, and gas extraction is isothermal; (2) only the change in gas 
pressure is considered, the total stress is assumed to be constant and there is no residual fracture aperture; (3) coal damage induced by coal shrinkage will directly affect permeability; (4) during gas extraction, the effects of effective stress and coal-matrix damage on coal permeability are equal. As mentioned in the previous section, the evolution of coal-mass permeability within an effective influence zone can be divided into two cases owing to gas extraction: (1) No damage exists in the coal matrix around the extracting borehole. Only fracture properties (like fracture aperture) will change because of gas extraction. How the coal-mass permeability will change in time-space during gas extraction. (2) The damage caused by gas extraction (coal shrinkage) and how the coal-mass permeability will change in time-space are considered.

This study will mostly focus on the evolution of coal-mass permeability with consideration of the above mentioned cases. Gas extraction changes the gas pressure of the coal-fracture element. In real engineering, the gas pressure will decrease with the increase of extraction time $t$, extraction pressure $p_{e}$, and the distance from the borehole center $r$. Considering the effect of gas extraction, the gas pressure is noted as follows:

$P=P\left(P_{0}, t, p_{e}, r\right)$

where $P_{0}$ is the initial gas pressure.

Taking the first case into consideration, no damage exists in the coal matrix around the extracting borehole during gas extraction. Based on Eq. (2), the relationship between effective stress and gas pressure under two different stress states can be written as follows:

$\sigma_{0}=\sigma_{t}-\alpha P_{0}$

$\sigma_{1}=\sigma_{t}-\alpha P_{1}\left(P_{0}, t, p_{e}, r\right)$

Superscripts 0 and 1 represent initial and certain stress states with extraction pressure $p_{e}$, respectively. Based on the abovementioned two equations, the following is obtained:

$\Delta \sigma=\alpha\left[P_{0}-P_{1}\left(P_{0}, t, p_{e}, r\right)\right]$

Therefore, Eq. (2) can be rewritten as follows:

$\frac{k_{1}}{k_{0}}=\exp \left\{-3 \alpha C_{f}\left[P_{0}-P_{1}\left(P_{0}, t, p_{e}, r\right)\right]\right\}$
If the gas pressure $P_{1}$ during gas extraction could be directly obtained, the change of coal-mass permeability under two different stress states is easy to obtain. However, $P_{1}$ is a complex parameter, and no specific and applicative theory in previous studies could calculate it; it could only be measured. The development of an appropriate equation to calculate $P_{1}$ is necessary.

When it comes to the second case, additional damage will occur within the effective influence zone because of gas extraction. With the additional damage taken into consideration, Fig. 2 shows the basic idea that the coal matrix will shrink to some extent, and additional damage will further occur inside the matrix after gas extraction. The development of coal-matrix damage will enlarge the opportunity for gas migration, and this study focuses on its effect on coal permeability.

As a result, damage variable $D$ of damage mechanics should be adopted. The assumption is that damage variable $D$ is a variable parameter with extraction pressure, extraction time, and distance from the extracting borehole center, which is similar to gas pressure. Zhu et al. (2013) demonstrated that the evolution of damage around the coal fracture controls the complex evolution of coal permeability under the influence of gas adsorption. Therefore, the permeability ratio is assumed to have a direct relationship with damage variable, and their relationship is defined as follows:

$\frac{k_{1}}{k_{0}}=\frac{1}{\left(1-D_{1}\right)^{m}}$

where $m$ is a coefficient connected to material properties, such as shrinkage or swelling. Superscripts 0 and 1 represent initial and certain conditions with gas extraction, respectively. Two models for one and two boreholes are developed to conduct a better parametric study of the effect of gas extraction on coal permeability.

2.3 Coal permeability model for one borehole during gas extraction

Two important effects of gas extraction on coal-mass permeability are mainly concerned with the coal permeability model: one is the change in fracture aperture, and the other is the accumulation of damage 


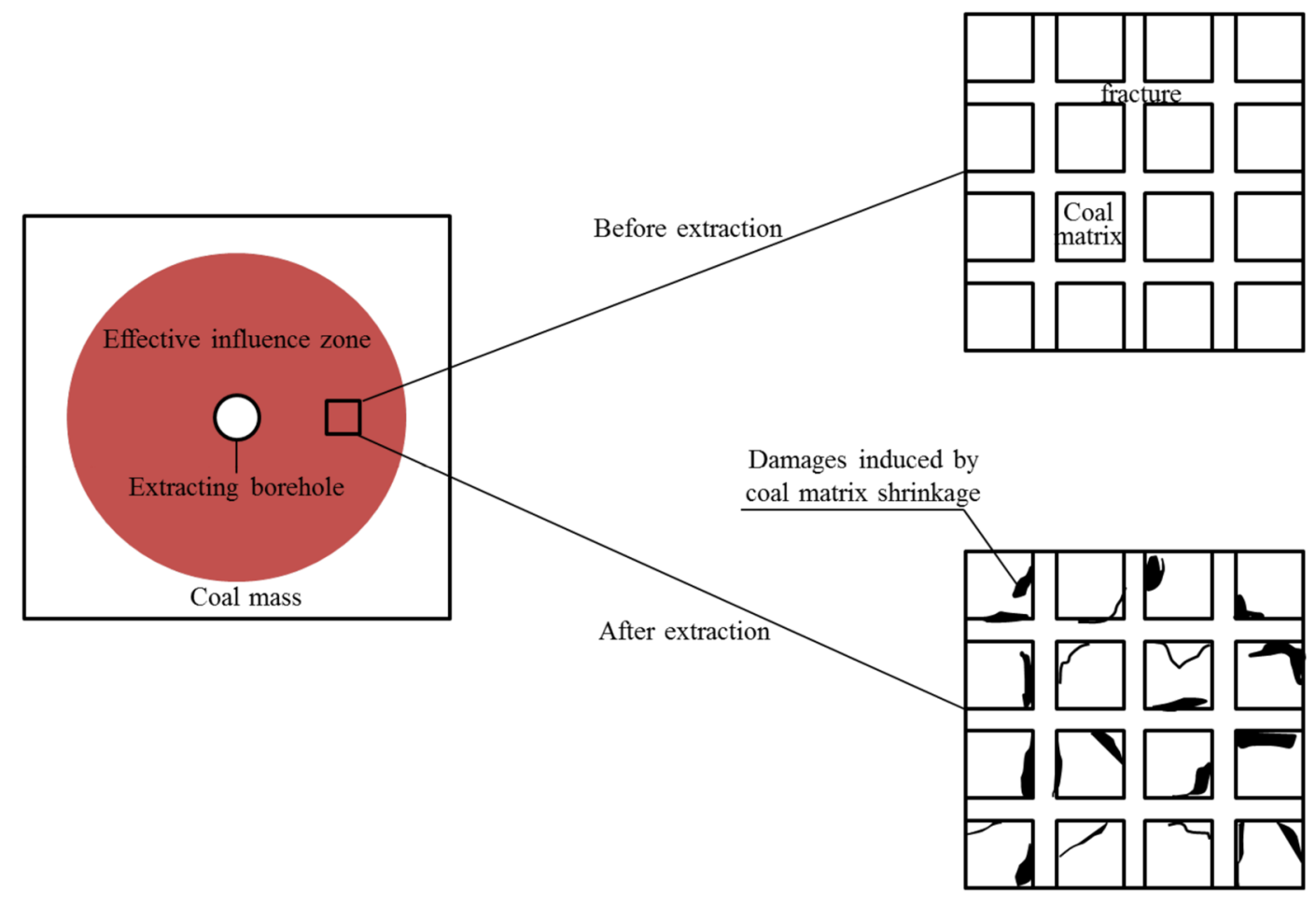

Fig. 2 Microcosmic change of coal-matrix after gas extraction

during gas extraction. Assuming that the two effects on permeability are linearly dependent, their effect factors are denoted as $K_{1}$ and $K_{2}$, respectively $\left(0<K_{1}<1,0<K_{2}<1\right.$, and $\left.K_{1}+K_{2}=1\right)$. Therefore, based on Eqs. (8) and (9), the coal-mass permeability within the effective influence zone can be written as follows:

$$
\begin{aligned}
\frac{k_{1}}{k_{0}}= & K_{1} \exp \left\{-3 \alpha C_{f}\left[P_{0}-P_{1}\left(P_{0}, t, p_{e}, r\right)\right]\right\} \\
& +K_{2} \frac{1}{\left(1-D_{1}\right)^{m}}
\end{aligned}
$$

The abovementioned equation is the main theory of the new coal permeability model during gas extraction.

However, two parameters should be obtained in Eq. (10): (1) $P_{1}$ of a function among initial gas pressure $P_{0}$, extraction time $t$, extraction pressure $p_{e}$, the distance from the borehole center $r$, and gas pressure $P_{1}$ and (2) damage variable $D$ of a suitable function with the same related parameters as $P_{1}$. The methods to develop the abovementioned two functions will be discussed later.
Owing to the effect of gas extraction, gas pressure will decrease within the effective influence zone. A longer extraction time corresponds to lower gas pressure. A larger extraction pressure corresponds to a faster decrease in gas pressure. A greater distance from the center of the extracting borehole indicates proximity to the initial gas pressure. The function can be preliminarily obtained based on these cases of gas extraction. Trimmer (1981) believed gas pressure presented a negative exponential attenuation with time in the laboratory when a saltation of gas pressure occurred. To some extent, the effect of gas extraction can also result in saltation for gas pressure. Thus, gas pressure is assumed to have a negative exponential relationship with extraction time, which can be given as follows:

$P_{1}=P_{0} e^{-\beta t}$

where $\beta$ can be called the attenuation coefficient of gas pressure within the effective influence zone. $\beta$ is assumed to be a ratio of extraction pressure $p_{e}$ and the distance from the borehole center $r$ to develop the function, which suggests the variation in gas pressure 
per distance and reflects the effect of gas extraction. Gas desorption is not considered in Eq. (11), which will affect the velocity of gas attenuation. Therefore, a coefficient $\delta$ is adopted in Eq. (12)

$P_{1}=P_{0} e^{-\delta \frac{p p}{r} t}$

$\delta$ is a coefficient connected to material properties to consider gas adsorption or desorption, which is not considered in Eq. (11). The unit of $P_{1}, P_{0}$, and $p_{e}$ is $\mathrm{MPa} ; r$ is $\mathrm{m}$, and $t$ is $\mathrm{d}$ (day).

Another problem is the function of damage variable $D$. During gas extraction, a larger release of gas pressure implies a more obvious shrinkage of and an additional damage in the coal matrix. Thus, the damage evolution of coal mass within the effective influence zone is assumed to be negative exponential, which is related to the change of gas pressure only. The damage variable $D_{1}$ is defined as follows:

$D_{1}=1-\exp \left(\frac{\Delta P}{P_{0}}\right)=1-\exp \left(\frac{P_{1}-P_{0}}{P_{0}}\right)$

The abovementioned equation suggests that additional damage is continuously generated during the release of gas pressure caused by gas extraction, and a direct relationship exists between the damage variable and the relative variation in gas. The gas pressure mentioned in this study is based on the effect of gas extraction and is not just the change in gas pressure as in the laboratory.

The combination of Eqs. (12) and (13) obtains the following:

$D_{1}=1-\exp \left(e^{-\delta \frac{p e}{r} t}-1\right)$

The permeability ratio can be obtained by considering the diameter $d$ of the extracting borehole and combining Eqs. (10), (12), and (14):

$$
\begin{aligned}
\frac{k_{1}}{k_{0}}= & K_{1} \exp \left[-3 \alpha C_{f} P_{0}\left(1-e^{-\delta \frac{p_{e}}{r} t}\right)\right] \\
& +K_{2} \exp \left(m-m e^{-\delta \frac{p e}{r} t}\right)
\end{aligned}
$$

The calculation model for one borehole is shown in Fig. 3. The coordinate of the research point is $(x, y)$, where $r=\sqrt{x^{2}+y^{2}}$. Based on the fourth assumption, $K_{1}=K_{2}=0.5$ is considered to simplify the calculation model.

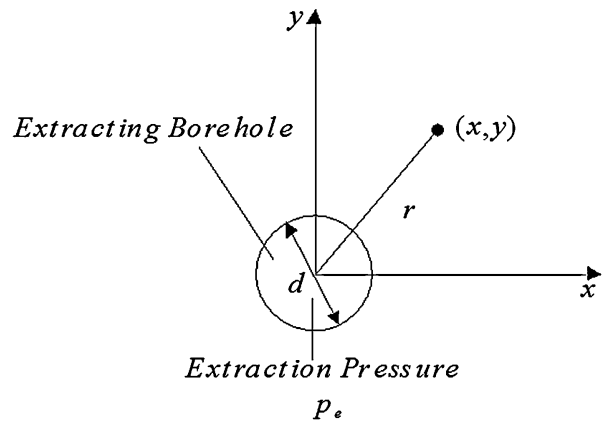

Fig. 3 Calculation model for one borehole

2.4 Coal permeability model for two boreholes during gas extraction

When two extracting boreholes are considered, the permeability ratio can be drawn as the accumulation of two parts of the effect of gas extraction in two boreholes. Figure 4 shows that $O_{1}$ is the origin of coordinates, and the $x$ direction is the line that connects the centers of two boreholes. The distances from two boreholes are $r_{1}=\sqrt{x^{2}+y^{2}}$ and $r_{2}=\sqrt{(l-x)^{2}+y^{2}}$.

Considering that gas extraction of two extracting boreholes is conducted at the same time, the gas pressure is provided below

$P_{1}=P_{0} e^{-\delta \frac{p_{e} 1}{r_{1}} t} e^{-\delta_{\frac{p_{e} 2}{r_{2}} t}}$

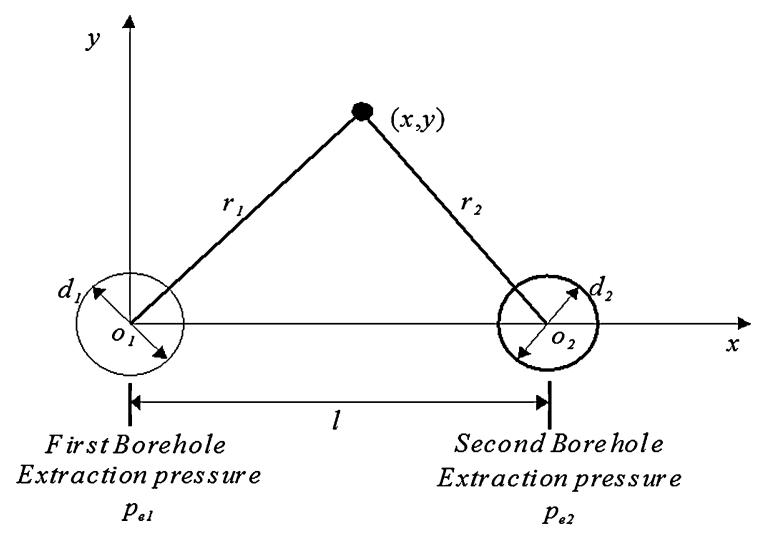

Fig. 4 Calculation model for two extracting boreholes 
Hence, the coal permeability ratio can be written as follows:

$$
\begin{aligned}
\frac{k_{1}}{k_{0}}= & K_{1} \exp \left[-3 \alpha C_{f} P_{0}\left(1-e^{-\delta_{\frac{p_{e} 1}{r_{1}} t}} e^{-\delta_{\frac{p}{r_{2}}} t}\right)\right] \\
& +K_{2} \exp \left(m-m e^{-\delta \frac{p_{e 1}}{r_{1}} t} e^{-\delta \frac{p_{e 2}}{r_{2}} t}\right)
\end{aligned}
$$

Based on the fourth assumption, $K_{1}=K_{2}=0.5$ is considered to simplify the calculation model.

\section{Model validation and parametric study}

\subsection{Calculation model}

To simplify the proposed model, only the coal permeability evolution along the $x$ direction was analyzed, and the extracting borehole was considered as a point in later analysis. The basic parameters for the two calculations are listed in Tables 1 and 2. The initial gas pressure is from the No. 8 Mine of Pingdingshan Coal Mining Group in China. The value for fracture compressibility $C_{f}$ is $0.43 \mathrm{MPa}^{-1}$ (Liu and Rutqvist 2010). Material coefficients $m$ and $\delta$ are considered as 1.0 to simplify the analysis (An intensive study should be conducted in future). Both reflect the capacity of gas adsorption or desorption.

\subsection{Results and analysis for one extracting borehole}

The effects of extraction time and extraction pressure are discussed in this section based on the equation of the permeability model for one borehole.
Table 2 Basic parameters for two boreholes

\begin{tabular}{lll}
\hline Parameters & Units & Value \\
\hline Initial gas pressure $P_{0}$ & $\mathrm{MPa}$ & 1.7 \\
Extracting borehole diameter $d$ & $\mathrm{~m}$ & 0.08 \\
Biot's coefficient $\alpha$ & $/$ & 1.0 \\
Extraction pressure $p_{e}$ & $\mathrm{MPa}$ & $0.01 ; 0.02 ; 0.03$ \\
Extraction pressure $p_{\mathrm{e} 2}$ & $\mathrm{MPa}$ & $0.05 ; 0.04 ; 0.03$ \\
Interval $l$ & $\mathrm{~m}$ & $1 ; 2 ; 3 ; 4 ; 5$ \\
Coordinate $x$ & $\mathrm{~m}$ & -4 to $l+4$ \\
Extraction time $t$ & $\mathrm{~d}$ & 120 \\
Material coefficients $m$ & $/$ & 1.0 \\
Material coefficients $\delta$ & $/$ & 1.0 \\
Fracture compressibility $C_{f}$ & $\mathrm{MPa}^{-1}$ & 0.43 \\
Effect factor $K_{1}$ & $/$ & 0.5 \\
Effect factor $K_{2}$ & $/$ & 0.5 \\
\hline
\end{tabular}

\subsubsection{Effect of gas extraction}

Taking one extracting borehole as an example, gas extraction caused additional damage to accumulate continuously, and this damage will influence coal permeability. Figure 5a shows that the permeability ratio (considering the damage) demonstrated less permeability reduction in the beginning of the extraction, in which the permeability ratio reduced to 0.93 . Induced by the release of gas, additional damage around the coal matrix accumulated constantly, but its effect was not large enough to resist the permeability decreasing induced by fracture closure. When the coal matrix shrank to some extent, an obvious permeability enhancement occurred. The increase in extraction time caused permeability to reach as high as 1.4 times
Table 1 Basic parameters for one borehole

\begin{tabular}{lll}
\hline Parameters & Units & Value \\
\hline Initial gas pressure $P_{0}$ & $\mathrm{MPa}$ & 1.7 \\
Extracting borehole diameter $d$ & $\mathrm{~m}$ & 0.08 \\
Biot's coefficient $\alpha$ & $/$ & 1.0 \\
Extraction pressure $p_{e}$ & $\mathrm{MPa}$ & $0.01 ; 0.02 ; 0.03 ; 0.04$ \\
Coordinate $x$ & $\mathrm{~m}$ & -4 to 4 \\
Extraction time $t$ & $\mathrm{~d}$ & 120 \\
Material coefficients $m$ & $/$ & 1.0 \\
Material coefficients $\delta$ & $/$ & 1.0 \\
Fracture compressibility $C_{f}$ & $\mathrm{MPa}^{-1}$ & 0.43 \\
Effect factor $K_{1}$ & $/$ & 0.5 \\
Effect factor $K_{2}$ & $/$ & 0.5 \\
\hline
\end{tabular}




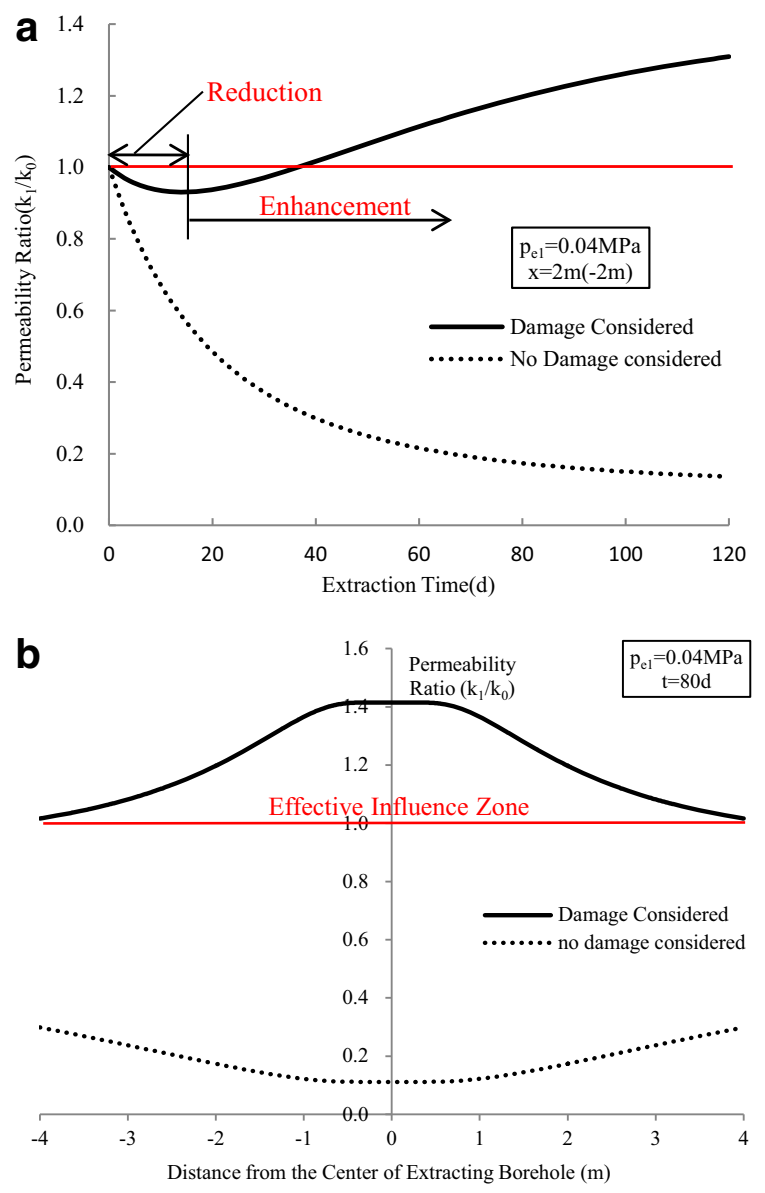

Fig. 5 a Permeability ratio evolution with extraction time. b Permeability ratio distribution within the effective influence zone

the initial permeability in this condition. However, the trend gradually weakened when gas decreased. When no damage was considered [using Eq. (8) only], the permeability ratio obviously decreased because of the enlargement of effective stress and closure of fracture, but its decreasing trend still gradually weakened after a long gas extraction. The results demonstrated that although the permeability ratio decreases because of the fracture closure, it is not large enough to change the increasing trend of coal permeability. The evolution of coal permeability is mainly controlled by the additional damage induced by gas extraction.

Figure $5 \mathrm{~b}$ shows the variation in coal permeability in space around the extracting borehole. Coal permeability was enhanced within the effective influence zone to some extent with consideration of the damage. A closer distance from the center of the extracting borehole implied a higher permeability ratio, and further distance from the center of the extracting borehole indicated that the permeability ratio was closer to 1 . The distribution was regular when no damage was considered. Therefore, the coal permeability model that considers damage is more consistent with real situations.

\subsubsection{Effect of extraction pressure}

A high extraction means a high velocity of gas release, which will induce quick coal-matrix shrinkage and accumulation of additional damage. Figure 6a shows that the extraction pressure also influenced coal permeability. Permeability ratio got increased when extraction pressure increased at the same extraction

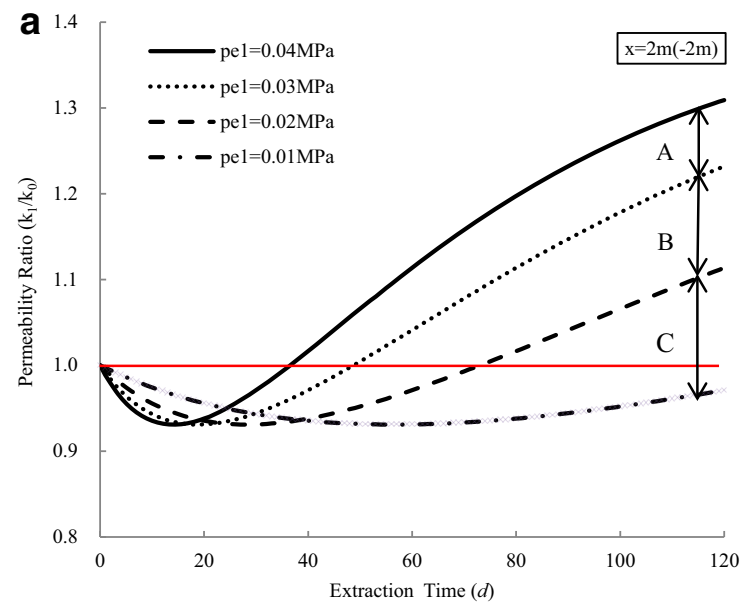

b
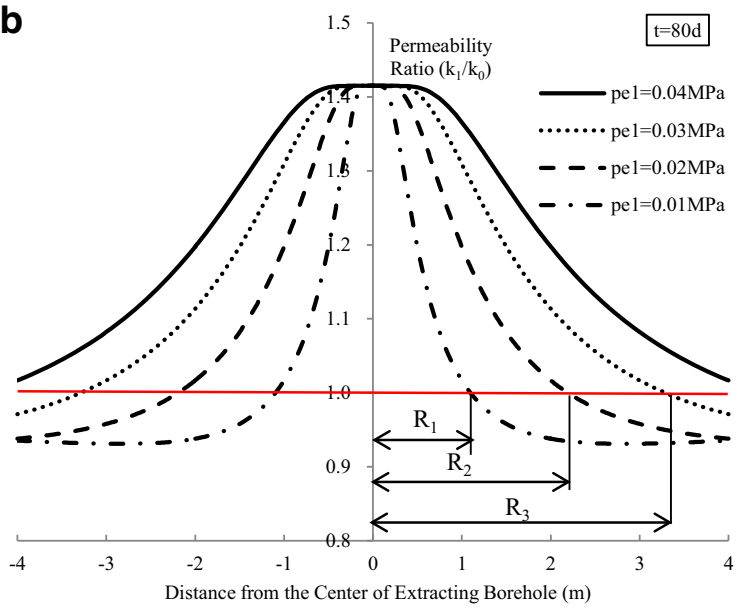

Fig. 6 a Permeability evolution with extraction time. b Permeability ratio distribution within the effective influence zone 
time and distance from the borehole center. In other words, a higher extraction pressure indicates an obvious permeability enhancement. Meanwhile, an obvious relationship exists among $\mathrm{A}, \mathrm{B}$, and $\mathrm{C}$ after a long extraction (A, B, and $\mathrm{C}$ are the relative amplifications of the permeability ratio between two different extraction pressures). The $\mathrm{C}>\mathrm{B}>\mathrm{A}$ relationship suggested that the relative amplification of the permeability ratio did not increase linearly with the increase of extraction pressure. As a result, a higher extraction pressure promotes but does not have a linear effect on permeability enhancement. The concept of higher pressure economical is not applicable to extraction pressure. Research on optimal extraction pressure is another important project that is worth conducting.

The distribution of the permeability ratio within the effective influence zone was "high middle and low around" and has a similar evolution in different extraction pressures (Fig. 6b). Given that Biot's coefficient and fracture compressibility were assumed to be constant in this model, coal permeability near the borehole slightly changed with different extraction pressures and reached the same peak in the four scenarios. However, in other locations of the effective influence zone, the evolution of permeability changed with different extraction pressures, that is, a higher extraction pressure generated a larger influence zone. By contrast, the results in Fig. 6b demonstrated that only some parts of the effective influence zone belonged to the permeability increasing zone, which can be called the effective radius of gas extraction. $R_{1}$, $R_{2}$, and $R_{3}\left(R_{1}, R_{2}\right.$, and $R_{3}$ are the effective radiuses of the permeability increasing zone) were 1.09, 2.19, and $3.28 \mathrm{~m}$ when the extraction pressures were $0.01,0.02$, and $0.03 \mathrm{MPa}$, respectively. Given that the extraction pressure in the No. 8 Mine of Pingdingshan Coal Mining Group was between 10 and $35 \mathrm{kPa}$, the permeability increasing zone of gas extraction can be considered as $2.5 \mathrm{~m}$ from the center of the extracting borehole.

\subsection{Results and analysis for two extracting boreholes}

The effect of the interval between two boreholes and the combination of different extraction pressures are discussed in this section based on the equation of permeability evolution for two boreholes developed in this study.

\subsubsection{Effect of the interval between two boreholes}

Creating a design for the distribution of extracting boreholes in situ is important. However, no theory is applicable for gas extraction so far, and people have addressed this problem through their experience. Based on measured data in the No. 8 Mine of Pingdingshan Coal Mining Group in China, the interval between two extracting boreholes is generally 1-2 $\mathrm{m}$. The new coal permeability model can provide an approximate guidance for in situ design of gas extraction.

Figure 7 shows that when the extraction pressure and extraction time are kept constant $\left(p_{\mathrm{e} 1}=\right.$ $p_{\mathrm{e} 2}=0.04 \mathrm{MPa}$, extraction time $\left.=80 \mathrm{~d}\right)$, the distribution of coal permeability with different $l(l=1$, $2,3,4,5 \mathrm{~m})$ was analyzed. Compared with the condition of one extracting borehole, gas extraction of two extracting boreholes improved the permeability ratio to some extent, especially in the place between two boreholes. The effective influence zone of two extracting boreholes was much larger than one borehole. The permeability ratio of the place between two extracting boreholes achieved more than 1.3 at least (Fig. 8). When the interval was 1 and $2 \mathrm{~m}$, the effect of gas extraction was large enough that it almost reached the permeability peak in the space between two extracting boreholes. The effect of gas extraction was becoming smaller when the interval was longer. The distribution of coal permeability presented a hump shape. Compared with the first situation (the interval was $1 \mathrm{~m}$ ), the coal permeability ratio of the center between two boreholes decreased to $99.86,98.79,96.53$, and $93.58 \%$. However, the effective influence zone became larger. Actual engineering experiences suggest that both the effective influence zone and permeability should be guaranteed. Therefore, based on the calculation results, the interval can be preliminarily taken as 3-4 $\mathrm{m}$ to guarantee center permeability of two boreholes at $95 \%$ of the peak. Other factors, such as extraction pressure, which also has an effect on the permeability distribution in space, must be considered in deciding the optimal interval between two boreholes (Fig. 6b). 
Fig. 7 Schematic view for calculation model with different intervals

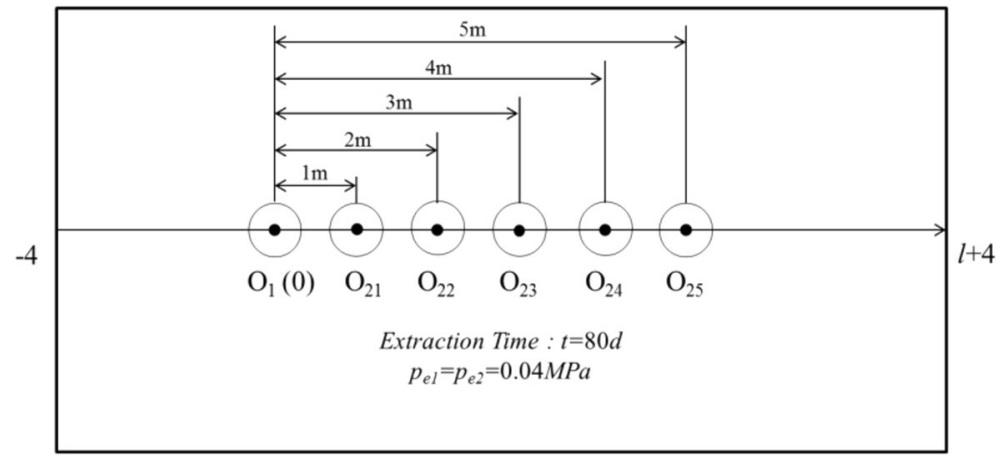

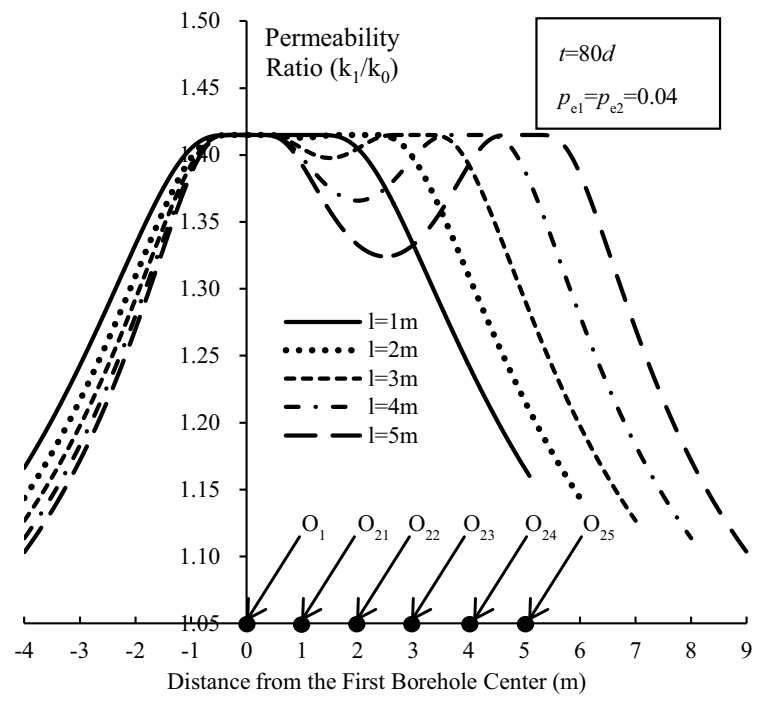

Fig. 8 Distribution of coal permeability with different $l(l=1$, $2,3,4,5 \mathrm{~m})$

\subsubsection{Effect of the extraction pressure combination}

Sometimes, extraction pressure is unstable and difficult to control, the effect on the extraction quality cannot be neglected. To study the effect of the extraction pressure combination, some related parameters should be fixed and the strength of gas extraction should be guaranteed. As a result, this calculation model considered an interval of $4 \mathrm{~m}$, extraction time of $80 \mathrm{~d}$ and a same extraction strength (the total extraction pressure of two boreholes remains the same value $0.06 \mathrm{MPa}$ ). Figure 9 shows the distribution of coal permeability with different extraction pressure combinations was analyzed for three different scenarios: (1) $p_{e 1}=0.01 \mathrm{MPa}, p_{e 2}=0.05 \mathrm{MPa}$; (2) $p_{e 1}=0.02 \mathrm{MPa}, p_{e 2}=0.04 \mathrm{MPa}$; and (3) $p_{e 1}=0.03$

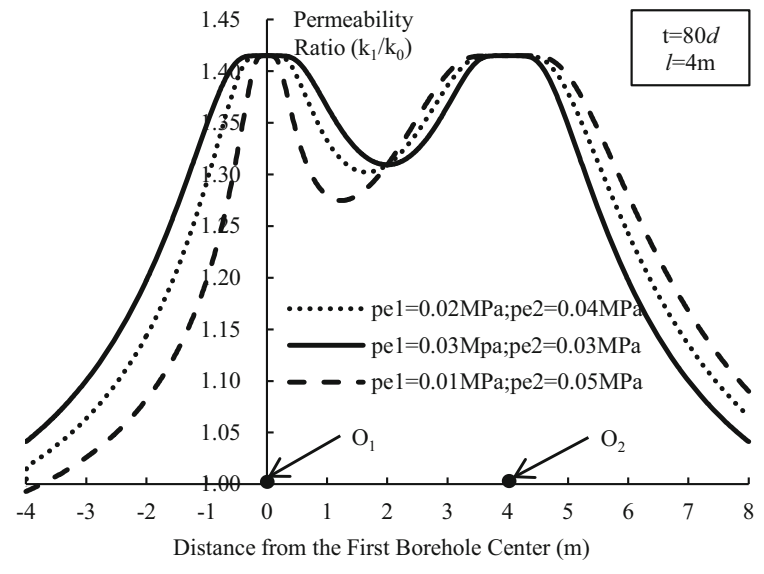

Fig. 9 Distribution of coal permeability with different extraction pressure combinations

$\mathrm{MPa}, p_{e 2}=0.03 \mathrm{MPa}$. As mentioned in Sect. 3.3.1, permeability in the place between two boreholes is important for real gas extraction. When it comes to the three scenarios, the minimum of permeability ratio between two boreholes successively reached 1.27, 1.31, 1.30 , and occurred at $1.24,2,1.68 \mathrm{~m}$ from the first borehole, respectively. The results suggested that the extraction pressure combination also affected the distribution of coal permeability to some extent. A larger difference between two extraction pressures implied a more asymmetric distribution of coal permeability, which will influence the quality of gas extraction. By contrast, a smaller difference between two extracting pressures implied a more stable effective influence zone. To ensure the quality of gas extraction, the difference between two extracting pressures should be controlled, and the extraction pressure for two neighboring boreholes should be equal as much as possible. 


\section{Discussion}

Gas extraction is the process of releasing gas. Based on this phenomenon, additional damage induced by the coal-matrix shrinkage was considered in the permeability model proposed in this study. The model emphasized the effect of gas release on coal permeability. The evolution of coal permeability with extraction time and permeability distribution is consistent with real situations. Figure 6 a shows that in the beginning of gas production, gas extraction can result in less permeability reduction and then an obvious permeability enhancement, which matches the conclusion of a previous study (Cui and Bustin 2005). Considering the effect of gas extraction, the results of the proposed model can be explained as follows: in the beginning of gas extraction, fracture aperture closes, and the permeability decreasing induced by fracture closure is larger than the permeability increasing induced by additional damages. However, when the extraction continues, the coal-matrix shrinkage will cause new damage to accumulate, which enlarges the volume of voids and increases the opportunity for gas migration and percolation.

Previous measured data have shown that coal permeability significantly increases with continued gas production in the San Juan Basin Fruitland formation (Mavor and Vaughn 1998). Mavor and Vaughn conducted tests at three wells, and their test data are described in Fig. 10, in which coal permeability increased by as much as 2.7 and 7.1 times when gas pressure decreased. By taking advantage of pressure-buildup (PBU) tests with three data points per well, Palmer (2009) obtained permeability results from ten wells, and these pressure/permeability data were digitized by Shi and Durucan (2010). The test data of the first point on each well were the initial pressure and initial permeability of this well, and the test data of wells A-1 and A-5 are presented in Fig. 10. All the results suggest that the trend of the proposed model results matches the permeability changes from the previous testing data. Similar matches were also found in the research of Palmer and Mansoori (1996) and Cui and Bustin (2005). However, compared with the magnitude of previous testing data, the permeability ratio of the coal permeability model proposed in this study is quite small. Three factors may result in this phenomenon:

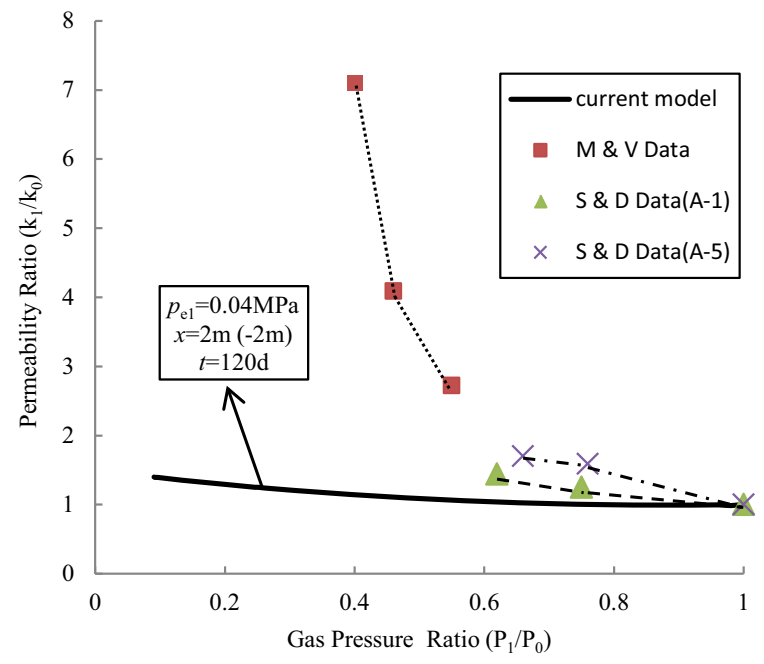

Fig. 10 Comparison between the model results and the observed data

1. Assumptions: there are four basic assumptions for the coal-gas permeability model. As for real engineering, the total stress cannot remain constant. The effective stress is affected by gas releasing and also by the change of total stress. Besides, both the effects of fracture closure and matrix shrinkage would influence coal permeability. However, it is difficult to figure out each ratio of the effects on coal permeability. Therefore, an intensive study should be conducted on $K_{1}$ and $K_{2}$.

2. Different conditions: the model is based on extracting boreholes, which are much smaller than the testing wells. Obvious scale effects exist. Gas extraction is the only condition considered in the model, and gas release is the only basic point in derivation. Meanwhile, the San Juan Basin Fruitland formation considered the effect of water saturation, which would also influence coal permeability (Han et al. 2010).

3. Different parameters: the model is proposed to study the evolution and distribution of coal permeability during gas extraction. The effects of extraction time, extraction pressure, borehole distribution, and extraction pressure combination are the concerns in this study. Meanwhile, the curve shown in Fig. 10 is only at one specific condition with $p_{\mathrm{e}}=0.04 \mathrm{MPa}$, and extraction time lasts only 4 months. The permeability ratio 
will increase with the increase of extraction pressure and extraction time.

4. Uncertain parameters: during the model development, the fracture compressibility $C_{f}$ is a calibrated value quoted from the model proposed by Liu and Rutqvist (2010). It is an alterable parameter affected by numerous factors, such as pore volume and effective stress. A larger $C_{f}$ implies a higher permeability ratio. Besides, the simplification of coefficients $m, \delta$ and $\alpha$ may be the other reason. For example, both $m$ and $\delta$ have a positive correlation with permeability ratio. The determination and effects of these uncertain parameters, which are connected to coal-matrix properties (swelling or shrinkage induced by gas adsorption or desorption), require intensive research.

As an artificial engineering disturbance, gas extraction is first considered to result in additional damages around boreholes, which will affect permeability distribution in time and space. However, real engineering does not consist of only one or two extracting boreholes. Gas extraction is more complex and intense, such that a large amount of roadway air will flood into the extracting borehole driven by negative pressure (Xia et al. 2014), which considerably affects gas migration. Admittedly, the coal permeability model proposed in this study is basic and simplified. Additional laboratory and field experiments should be conducted to further validate the proposed model. A new model for coal permeability of gas extraction based on micro-mechanical analysis should be explored in the future.

\section{Conclusions}

In situ gas extraction is the main measure adopted by numerous mines to achieve mining safety standards. One key parameter for gas extraction is coal permeability. Given the coal-matrix shrinkage and damage induced by gas extraction, the evolution and distribution of coal permeability will change in time and space. A new coal permeability model was proposed based on the effect of gas extraction, and a parametric study was conducted under some certain conditions. The major conclusions are as follows:

1. A unique coal permeability model was proposed based on effective stress and additional damage to describe the spatial and temporal distribution of coal permeability within the effective influence zone.

2. With the increase of extraction time, the permeability ratio decreased to 0.93 in the beginning of extraction, but then it almost enhanced to 1.4. Extraction pressure obviously influences coal permeability within the effective influence zone. However, the relative amplification of the permeability ratio does not increase linearly with the increase of extraction pressure. A higher extraction pressure implies a larger effective radius of the permeability increasing zone. As for No. 8 Mine of Pingdingshan Coal Mining Group, the effective radius can be considered as $2.5 \mathrm{~m}$ preliminarily.

3. Both intervals of two extracting boreholes and different extraction pressure combinations have influence on the distribution of coal permeability. The permeability ratio in the space between two extracting boreholes achieved more than 1.3 at least, $93 \%$ of the peak. Meanwhile, a larger difference between two extracting pressures implied a more asymmetric distribution of coal permeability. To guarantee the quality of gas extraction, the difference between two extracting pressures should be controlled as much as possible. The interval can be preliminarily taken as 3-4 m to guarantee center permeability of two boreholes at $95 \%$ of the peak.

4. The model was developed for relatively simple situations. Only changes in gas pressure, extraction time, and extraction pressure were considered. Additional theoretical studies and simulations on the relationship between mechanical deformation and additional damages should be conducted to more accurately model the effect of gas extraction.

Acknowledgments This research was funded by the State Key Basic Research Program of China (No. 2011CB201201), the Sanjin Scholars Program of China, and the National Natural Science Foundation of China (Nos. 51204113 and 51204112).

\section{References}

Chen Z, Pan Z, Liu J, Connell LD, Elsworth D (2011) Effect of the effective stress coefficient and sorption-induced strain on the evolution of coal permeability: experimental observations. Int J Greenh Gas Control 5:1284-1293 
Clarkson CR (2009) Case study: production data and pressure transient analysis of horseshoe canyon CBM wells. J Can Pet Technol 48:27-38

Connell LD, Lu M, Pan Z (2010) An analytical coal permeability model for tri-axial strain and stress conditions. Int $\mathbf{J}$ Coal Geol 84:103-114

Cui X, Bustin RM (2005) Volumetric strain associated with methane desorption and its impact on coalbed gas production from deep coal seams. AAPG Bull 89:1181-1202

Enever J, Henning A (1997) The relationship between permeability and effective stress for Australian coal and its implications with respect to coalbed methane exploration and reservoir model. In: Proceedings of the 1997 international coalbed methane symposium, 1997. University of Alabama, Tuscaloosa, AL, USA, pp 13-22

Gray I (1987) Reservoir engineering in coal seams: part 1-the physical process of gas storage and movement in coal seams. SPE Reserv Eng 2:28-34

Han F, Busch A, van Wageningen N, Yang J, Liu Z, Krooss BM (2010) Experimental study of gas and water transport processes in the inter-cleat (matrix) system of coal: anthracite from Qinshui Basin, China. Int J Coal Geol 81:128-138

Harpalani S, Schraufnagel RA (1990) Shrinkage of coal matrix with release of gas and its impact on permeability of coal. Fuel 69:551-556

Hu YQ, Zhao YS, Yang D, Kang ZQ (2010) Experimental study of effect of temperature on permeability characteristics of lignite. Chin J Rock Mech Eng 29(8):1585-1589 (in Chinese)

Hu S, Zhou F, Liu Y, Xia T (2014) Effective stress and permeability redistributions induced by successive roadway and borehole excavations. Rock Mech Rock Eng. doi:10. 1007/s00603-013-0544-y

Izadi G, Wang SG, Elsworth D, Liu J, Wu Y, Pone D (2011) Permeability evolution of fluid-infiltrated coal containing discrete fractures. Int J Coal Geol 85(2):202-211

Jaeger JC, Cool NGW, Zimmerman RW (2007) Fundamentals of rock mechanics. Blackwell Publishing, Malden

Jasinge D, Ranjith PG, Choi SK (2011) Effects of effective stress changes on permeability of latrobe valley brown coal. Fuel 90:1292-1300

Liu H, Rutqvist J (2010) A new coal-permeability model: internal swelling stress and fracture-matrix interaction. Transp Porous Media 82:157-171

Mavor M, Vaughn J (1998) Increasing coal absolute permeability in the San Juan Basin fruitland formation. SPE Reserv Eval Eng 1:201-206

McKee CR, Bumb AC, Koenig RA (1987) Stress-dependent permeability and porosity of coal. In: International coalbed methane symposium. University of Alabama, Tuscaloosa, Alabama, pp 33-45

Meng Z, Zhang J, Wang R (2011) In-situ stress, pore pressure and stress-dependent permeability in the Southern Qinshui Basin. Int J Rock Mech Min Sci 48:122-131

Palmer I (2009) Permeability changes in coal: analytical modeling. Int J Coal Geol 77:119-126

Palmer I, Mansoori J (1996) How permeability depends on stress and pore pressure in coalbeds: a new model. In: Copyright 1996 SPE annual technical conference and exhibition. Society of Petroleum Engineers, Inc., Denver, Colorado
Palmer I, M Mavor, Gunter B (2007) Permeability changes in coal seams during production and injection. In: International coalbed methane symposium. University of Alabama, Tuscaloosa. Paper0713

Pan Z, Connell LD (2007) A theoretical model for gas adsorption-induced coal swelling. Int J Coal Geol 69:243-252

Pan Z, Connell LD (2012) Modelling permeability for coal reservoirs: a review of analytical models and testing data. Int J Coal Geol 92:1-44

Pan Z, Connell LD, Camilleri M (2010) Laboratory characterisation of coal reservoir permeability for primary and enhanced coalbed methane recovery. Int $\mathrm{J}$ Coal Geol $82: 252-261$

Pekot LJ, Reeves SR (2002) Modeling coal matrix shrinkage and differential swelling with $\mathrm{CO} 2$ injection for enhanced coalbed methane recovery and carbon sequestration applications. Topical Report, Contract No. DE-FC2600NT40924, US DOE, Washington, DC (November 2002)

Reiss LH (1980) The reservoir engineering aspects of fractured formations. Gulf Publishing Co., Houston

Seidle JP, Huitt L (1995) Experimental measurement of coal matrix shrinkage due to gas desorption and implications for cleat permeability increases. In: International meeting on petroleum engineering, pp 575-582

Seidle JP, Jeansonne MW, Erickson DJ (1992) Application of matchstick geometry to stress dependent permeability in coals. In: SPE 24361, SPE rocky mountain regional meeting. Casper, Wyoming, pp 433-444

Shi J, Durucan S (2004a) A numerical simulation study of the Allison unit CO2-ECBM pilot: the impact of matrix shrinkage and swelling on ECBM production and $\mathrm{CO} 2$ injectivity. In: Proceedings of 7 th international conference on greenhouse gas control technologies, pp 431-439

Shi J, Durucan S (2004b) Drawdown induced changes in permeability of coalbeds: a new interpretation of the reservoir response to primary recovery. Transp Porous Media 56:1-16

Shi J, Durucan S (2010) Exponential growth in San Juan Basin Fruitland coalbed permeability with reservoir drawdown: model match and new insights. SPE Reserv Eval Eng 13:914-925

Siriwardane H, Haljasmaa I, McLendon R, Irdi G, Soong Y, Bromhal G (2009) Influence of carbon dioxide on coal permeability deter by pressure transient methods. Int J Coal Geol 77:109-118

Trimmer DA (1981) Design criteria for laboratory measurements of low permeability rocks. Geophys Res Lett 8(9):973-975

Wu Y, Liu J, Chen Z, Elsworth D, Pone D (2011) A dual poroelastic model for $\mathrm{CO}_{2}$-enhanced coalbed methane recovery. Int J Coal Geol 86:177-189

Xia T, Zhou F, Liu J, Hu S, Liu Y (2014) A fully coupled coal deformation and compositional flow model for the control of the pre-mining coal seam gas extraction. Int $\mathrm{J}$ Rock Mech Min Sci 72:138-148

Xie H, Zhou H, Cheng G, Zhou F (2013) On theoretical and modeling approach to mining enhanced permeability for simultaneous exploitation of coal and gas. J China Coal Soc 38:1101-1108 (in Chinese)

Zhu W, Wei C, Liu J, Xu T, Elsworth D (2013) Impact of gas adsorption induced coal matrix damage on the evolution of coal permeability. Rock Mech Rock Eng 46:1353-1366 